\title{
Gender Differences in Peripheral Vascular Disease
}

\author{
Kristofer Schramm, MD ${ }^{1}$ Paul J. Rochon, MD ${ }^{1}$ \\ ${ }^{1}$ Department of Radiology, University of Colorado School of \\ Medicine, Aurora, Colorado \\ Semin Intervent Radiol 2018;35:9-16
}

\begin{abstract}
Address for correspondence Paul J. Rochon, MD, Department of Radiology, University of Colorado School of Medicine, 13001 E 17th PI, Aurora, CO (e-mail: paul.rochon@ucdenver.edu).
\end{abstract}

\author{
Abstract \\ Keywords \\ - interventional \\ radiology \\ - peripheral arterial \\ disease \\ - gender \\ - medical therapy
}

In the past 20 years, peripheral artery disease (PAD) has been increasingly recognized as a significant cause of morbidity and mortality in the United States. PAD has traditionally been identified as a male-dominant disease; however, recent population trends and studies in PAD suggest that women are affected at least as often as men. Women comprise a larger population of the elderly than men, as well as an increasing proportion of patients with PAD. Much of the existing research on PAD has focused on whole populations, and gender-specific data on PAD is sparse. This review focuses on gender-specific differences in presentation, management, and outcomes of PAD intervention that are important considerations for the interventional radiologist.
Objectives: Upon completion of this article, the reader will be able to describe the gender differences between men and women in the etiology, presentation, and treatment of peripheral arterial disease.

Accreditation: This activity has been planned and implemented in accordance with the accreditation requirements and policies of the Accreditation Council for Continuing Medical Education (ACCME) through the joint providership of Tufts University School of Medicine (TUSM) and Thieme Medical Publishers, New York. TUSM is accredited by the ACCME to provide continuing medical education for physicians.

Credit: Tufts University School of Medicine designates this journal-based CME activity for a maximum of $\mathbf{1} \boldsymbol{A M A}$ PRA Category 1 Credit $^{\mathrm{TM}}$. Physicians should claim only the credit commensurate with the extent of their participation in the activity.

Cardiac and vascular disease is the leading cause of death for women in the United States. ${ }^{1}$ Despite the advances in understanding female coronary vascular disease in the past 20 years, female peripheral vascular disease remains under-recognized as a cause of significant morbidity and mortality by both the medical community and public. $^{2}$ During the 20th century, physicians failed to realize the impact of coronary artery disease in women which ultimately led to significant preventable death from heart disease. ${ }^{3}$ Currently in the 21st century, peripheral arterial disease is beginning to be recognized as a life- and lifestyle-threatening disease in women. Peripheral artery disease (PAD) affects between 5 and 10 million people in the United States, and is associated with similar morbidity, mortality, and economic healthcare costs as both heart disease and stroke. ${ }^{4}$ PAD is more prevalent as age increases, and women make up a larger proportion of the elderly than men. Needless to say, a greater understanding of the effects of peripheral arterial disease on women's health will be vital in healthcare in the coming years as the nation's population ages. ${ }^{5}$ Despite the clear indications to advance the understanding of the impact of vascular disease on women's health, women remain underrepresented in contemporary clinical research. ${ }^{6}$ Consequently, gender-specific distinctions in risk factors, management, and outcomes of vascular disease remain a gray area for physicians. This creates a clear and vital need for an increase in awareness of the burden of vascular disease in women. This article focuses on specific gender trends in peripheral vascular disease in an attempt to shed light on this critical issue.

\section{Gender-Specific Risk Factors for Vascular Disease}

Many traditional risk factors for the development of peripheral vascular disease are shared between both genders. Hyperlipidemia, diabetes mellitus, hypertension, smoking history, and obesity are strong risk factors for the development of vascular disease for both sexes. ${ }^{7}$ The prevalence of vascular disease increases for women after menopause, ${ }^{8}$ and a woman's risk of developing symptomatic vascular disease is determined by her risk factors present during the postmenopausal period. ${ }^{9}$ In the United States, $67 \%$ of women have
Issue Theme Women's Health; Guest Editors, Kimi L. Kondo, DO, FSIR and Laura K. Findeiss, MD, FSIR
Copyright (C) 2018 by Thieme Medical Publishers, Inc., 333 Seventh Avenue, New York, NY 10001, USA. Tel: +1(212) 584-4662.
DOI https://doi.org/ 10.1055/s-0038-1636515. ISSN 0739-9529. 
one or more major vascular risk factors at the time of menopause onset, and this percentage increases with older age. Early control of these medical risk factors is imperative for the prevention of PAD.

Tobacco use is the leading preventable cause of vascular disease in women, and especially so for those younger than 50 years. Patients who smoke are at a fourfold increased risk for the development of symptomatic PAD when compared with nonsmokers. ${ }^{10}$ The likelihood of developing symptomatic PAD is directly correlated to age of smoking onset and total pack-years smoked. While the long-term impacts of prolonged smoking may not be able to be totally mitigated, risk of development of symptomatic arterial disease may be improved by early smoking cessation. ${ }^{11}$ Aggressive public health initiatives in recent years have led to declining smoking rates in both men and women. The Centers for Disease Control and Prevention has recently reported that the incidence of smoking has decreased over the past 50 years from $42.4 \%$ in 1965 to $16.8 \%$ in 2014 . This progress is encouraging; however, there has been a steeper decline in the rates of male smoking as compared with female smoking. As a result, women are assuming a larger number of smoking-related diseases by percentage. ${ }^{12}$ Therefore, women should be more strongly targeted during future smoking cessation tactics.

It has been long assumed that estrogen was associated with a protective effect against the development of atherosclerotic disease in women. Consequently, hormone replacement therapy (HRT) was seen as a means to combat the effects of atherosclerosis in postmenopausal females. The Rotterdam Study of 2,196 females initially suggested that HRT of 1 year or longer was associated with a 52\% risk reduction of PAD. ${ }^{13}$ More recently, however, larger randomized trials by the Women's Health Initiative (WHI) and the Heart and Estrogen/Progestin Replacement (HERS) trials have demonstrated no benefit from HRT in the prevention of peripheral vascular disease. ${ }^{14,15}$ In fact, certain studies by the WHI have actually suggested that HRT is associated with more events related to peripheral vascular disease. ${ }^{16}$ These studies provide evidence that sex hormones have a pronounced effect on the development of atherosclerosis, although the exact relationship must be further studied to provide a future target for therapy.

Population studies have long documented the association between diabetes and PAD. ${ }^{17}$ Atherosclerosis is responsible for the most deaths and disability in the diabetic patient population, and accounts for $44 \%$ of all cause fatalities in this cohort. ${ }^{18}$ There are clear gender disparities in the development of vascular disease in patients with diabetes. Women with diabetes more commonly develop symptomatic PAD than men. The presence of diabetes in women nearly doubles their risk for development of intermittent claudication (IC) when compared with men. ${ }^{19}$ Therefore, aggressive blood sugar modulation is of paramount importance in the prevention of PAD in females.

Obesity is also a shared risk factor for the development of PAD in both men and women. The risk of PAD development depends both on the severity of obesity and body fat com- position and fat mass distribution. ${ }^{20,21}$ Cardiovascular disease has been linked to abdominal deposition of fat, as the visceral adipose tissue is responsible for the secretion of adipokines. These hormones modify metabolic parameters, such as insulin resistance, while also producing proatherogenic effects by inducing endothelial damage and increasing inflammatory markers. ${ }^{22}$ Waist circumference has long served as a surrogate for patient risk related to obesity. ${ }^{21}$ Women have a lower threshold for abdominal circumference as opposed to men when it comes to abdominal obesity and the association with cardiovascular disease. In women, an abdominal circumference of $88 \mathrm{~cm}$ is associated with increased risk, as opposed to $102 \mathrm{~cm}$ in males. ${ }^{23}$ Aggressive weight loss tactics are therefore advocated when treating females at risk for PAD.

- Table 1 outlines the risk factors associated with PAD in women compared with men.

\section{Prevalence of PAD in Women}

Peripheral artery disease can be diagnosed with the assistance of ankle brachial index (ABI), ultrasound, computed tomography angiography, magnetic resonance angiography, and/or catheter angiography. The hallmark symptom of PAD is IC, but many cases of asymptomatic PAD are diagnosed via $A B I$. The ABI serves as the typical screening method for PAD, as it is a noninvasive and inexpensive test to determine the presence of lower extremity vascular disease. Historically, most population-based studies have used a cutoff of less than 0.9 as a defining characteristic of PAD, as this was correlated to anatomic abnormalities on catheter angiography. $^{24}$ This has been recently revised by the American College of Cardiology Foundation/American Heart Association Task Force due to the surmounting research that an ABI of less than 1.0 is associated with elevated cardiovascular risk. $^{25}$ These institutions have suggested the higher threshold for diagnosis of PAD by ABI, and as a result, asymptomatic PAD is far more prevalent in the population than previously thought. $^{26}$

PAD prevalence and incidence are intimately age related. Allison et al estimated the rates of PAD as a factor of age by combining seven community-based studies. ${ }^{27}$ In 2012, these data were adapted to calculate gender-specific prevalence rates and combined with the 2010 census data to provide the most up-to-date calculations of the burden of PAD on the

Table 1 Risk factors of PAD in women

\begin{tabular}{|l|l|}
\hline Diabetes & $\begin{array}{l}\text { Presence of diabetes doubles the risk of IC } \\
\text { as compared with males }\end{array}$ \\
\hline Tobacco use & $\begin{array}{l}\text { Females are assuming a larger number of } \\
\text { smoking-related diseases by percentage }\end{array}$ \\
\hline Obesity & $\begin{array}{l}\text { Waist circumference required for } \\
\text { increased cardiovascular risk is smaller } \\
\text { than for males }\end{array}$ \\
\hline
\end{tabular}

Abbreviations: IC, intermittent claudication; PAD, peripheral arterial disease. 
population. While PAD has typically been thought of as a male-dominant disease process, when accounting for the greater representation of women in the elderly population, there are more women than men with PAD among U.S. adults older than 40 years. ${ }^{28}$ Additionally, Diehm et al $^{29}$ noted that the prevalence of PAD increased more as a function of age for women than it did for men, with women older than 85 years having a prevalence of $39 \%$ (males $27 \%$ ).

\section{Clinical Presentation of PAD in Women}

Intermittent claudication is the hallmark manifestation of PAD; however, the majority of patients with PAD are either asymptomatic or have atypical symptoms. It is estimated that only around $10 \%$ of patients with PAD will present with classic symptoms of IC. Consequently, population studies have estimated that as many as $50 \%$ of patients with PAD will present with atypical leg symptoms, and as many as $40 \%$ of patients with PAD will be asymptomatic. ${ }^{30}$ Asymptomatic PAD (defined as an ABI $<0.9$ in the absence of symptoms) is observed in both men and women; however, there is a significant gender-based difference in the prevalence of asymptomatic PAD in women (13\%) as opposed to men $(9 \%) .{ }^{31}$ It has been suggested that there is a prolonged latent phase in the progression of asymptomatic PAD to symptomatic PAD. Therefore, given the relative prevalence of asymptomatic PAD in women, early detection of asymptomatic PAD in women is of utmost importance to control risk factors and inhibit disease progression.

Men and women have different presentations of PAD. First described by the Women's Health and Aging Study, asymptomatic PAD is most common in the elderly female population, with up to $63 \%$ of elderly females with an ABI of less than 0.9 demonstrating no exertional leg symptoms. ${ }^{32,33}$ In addition to the propensity of PAD to be asymptomatic in females, the Walking and Leg Circulation Study (WALCS) cohort demonstrated that women are twice as likely to have atypical exertional leg symptoms. ${ }^{32,34}$ Unfortunately, the prevalence of atypical symptoms in female patients combined with greater incidence of asymptomatic PAD in females often leads to delayed diagnosis. Exactly why women have a higher incidence of asymptomatic PAD when compared with men is not well understood. Many have theorized several possibilities for this disparity. For instance, women may be less likely to report physical symptoms than men. Importantly, women tend to be older at the time of diagnosis than men, and symptoms classic of PAD may be masked in this age group by an increase in the prevalence of osteoarthritis or the decrease in activity levels that occur with aging.

The WACLS cohort demonstrated several other key gender-based differences in the presentation of IC. For instance, the treadmill distance to onset of claudication was 33\% shorter for females than it was for males at the time of diagnosis. In addition, the maximum treadmill walking distance was $23 \%$ shorter for females than it was for males at the time of initial presentation. Women with symptomatic PAD also had slower walking speeds than males. These findings suggest that women may have increased functional impairment at initial presentation than men with a similar vascular disease burden. ${ }^{34}$ Recognition of these differences is key in recognizing the impact that PAD has on quality of life in the female population.

-Table 2 outlines the clinical presentation of PAD in women.

\section{Medical Therapy in the Treatment of Female PAD}

The medical treatment of PAD has two major goals: (1) symptom management to maintain physical activity and (2) to reduce the progression of atherosclerosis to reduce the risk of cardiac or cerebrovascular event. These goals are met by the reduction of risk factors where appropriate, maximal medical management to control symptoms, and surgical or endovascular revascularization. Treatment of coexisting medical contributors to PAD such as hyperlipidemia, hypertension, and diabetes has been shown to reduce morbidity and mortality associated with PAD. ${ }^{35}$ In addition, smoking cessation is of paramount importance in patients with PAD, as it is associated with an increase in revascularization patency rates and a rapid reduction of cardiovascular risk. $^{36}$

Cilostazol, a phosphodiesterase type 3 inhibitor, is the only FDA-approved pharmacologic treatment for claudication. It has a dual effect for claudicants, both the direct result of effects on protein kinase A. Cilostazol indirectly increases levels of protein kinase $A$, which inhibits platelet aggregation. Additionally, protein kinase A also prevents the activation of enzymes that are important for small vessel smooth muscle contraction, therefore providing a vasodilatory effect. Meta-analysis and systematic reviews have shown improvement in peak walking distance, claudication onset distance, and quality of life in claudicants treated with cilostazol. ${ }^{37}$ Pooled data from the literature as reported by Pande et al included 532 women out of 2,251 patients, and gender-

Table 2 Presentation of PAD in women

\begin{tabular}{|l|l|}
\hline Asymptomatic PAD & More common in women $^{31}$ \\
\hline Age at presentation & $\begin{array}{l}\text { Women present with symptoms } \\
\text { at an older age than men }\end{array}$ \\
\hline Claudication distance & $\begin{array}{l}\text { Distance to claudication onset is } \\
\text { shorter for women }\end{array}$ \\
\hline Latent phase PAD & $\begin{array}{l}\text { Longer latent phase of PAD in } \\
\text { women may lead to greater risk } \\
\text { of CLI at presentation }\end{array}$ \\
\hline Atypical leg symptoms & More common in women ${ }^{32,34}$ \\
\hline Critical Limb Ischemia & $\begin{array}{l}\text { Women are more likely to pre- } \\
\text { sent with CLI }\end{array}$ \\
\hline Walking speeds & $\begin{array}{l}\text { Slower walking speeds in women } \\
\text { diagnosed with IC as compared } \\
\text { with males }\end{array}$ \\
\hline
\end{tabular}

Abbreviations: CLI, critical limb ischemia; IC, intermittent claudication; PAD, peripheral arterial disease. 
specific analysis of these patients showed no significant difference in estimated treatment benefit between men and women. ${ }^{38}$ Accordingly, cilostazol remains an important option in the treatment armamentarium for IC in females.

Supervised exercise programs have long been recommended as first-line therapy for the treatment of claudication. It is thought that regular exercise increases collateral blood flow past areas of stenosis or obstruction, improves nitric oxide-dependent vasodilatation, and decreases systemic inflammation-all of which provide improved symptoms. There is a large body of evidence to support the clinical benefits of a supervised exercise program in improving both quality of life and limb performance. ${ }^{39}$ As such, the Society for Vascular Surgery currently gives supervised exercise a level $1 \mathrm{~A}$ recommendation in the setting of symptomatic PAD. ${ }^{40}$ A recent publication from the American Heart Association reviewed 32 randomized control trials on gender differences in supervised exercise programs. These trials encompassed 493 women treated with supervised exercise. These studies confirmed the benefit in claudication onset time, claudication distance, and peak walking distance in females; however, none of the studies reported genderspecific outcomes. ${ }^{28}$ Similarly, they examined several studies comparing supervised treadmill or walking training to either surgical or endovascular revascularization. Most of these studies confirmed symptomatic improvement in both the supervised exercise and revascularization arms of the studies; however, only one study reported gender-specific results, which did not influence outcome. ${ }^{41}$ Both male and female claudicants alike benefit from prescribed exercise.

Finally, antiplatelet therapy should be considered in all patients with PAD. The use of antiplatelet therapy in those with coronary or cerebral atherosclerotic events has been well documented, but the evidence for the use of this therapy in isolated PAD is weaker. However, some evidence exists regarding the benefit of antiplatelet therapy in patients with isolated PAD in the absence of coronary or cerebrovascular disease. The Antithrombotic Trialists' Collaboration showed a $23 \%$ reduction in vascular events in patients with PAD treated with antiplatelet medications. ${ }^{42}$ Current guidelines support the use of aspirin or clopidogrel as a single agent in patients with PAD who have suffered a previous myocardial infarction or stroke. Unfortunately, there are no published guidelines to support routine use of antiplatelet monotherapy for patients with asymptomatic PAD, although this approach is frequently utilized. ${ }^{43}$

\section{Selection for Lower Extremity Revascularization}

Ischemic ulceration, gangrene, rest pain, or lifestyle-limiting or disabling claudication serve as the primary indications for endovascular or open revascularization. Patients with critical limb ischemia (CLI), including those with rest pain, ulceration, or gangrene, have the strongest indications for operative intervention. Open surgical bypass and endovascular angioplasty and/or stent placement remain options for revascularization in both men and women.
Historically, there was a large gender gap in patient selection for lower extremity revascularization. In a 1994 study by Feinglass et al, men were twice as likely to be selected for revascularization as compared with women, even when baseline indications for limb salvage procedure were comparable. $^{44}$ More recently, in an analysis of 2.4 million PAD-related inpatient admissions, women were found to be significantly less likely than men to receive a surgical revascularization procedure. ${ }^{45}$ This same study also discovered that women with PAD are more likely than men to present for emergent medical attention with symptoms of CLI. The reasons for these findings are currently under investigation. It is hypothesized that the greater proportion of asymptomatic women with PAD, as well as the prevalence of atypical symptoms in the female population, may be related to late presentation of disease. Additionally, it has been postulated that atypical symptom presentation may make surgeons less likely to offer operative intervention.

\section{Gender Considerations and Outcomes after Lower Extremity Revascularization}

Gender-specific data on outcomes after open lower extremity revascularization have associated female gender with worse surgical outcomes. In the largest published series of 9,217 patients undergoing extra-anatomic infrainguinal bypass, female gender was related to graft failure as was smoking (odds ratio of 1.29 and 1.36 , respectively). ${ }^{46}$ In patients presenting with CLI for open revascularization, women were found to be more likely to suffer from wound complications, limb loss, and mortality than their male counterparts. ${ }^{47}$ Female gender has also been consistently demonstrated to represent an independent risk factor for wound infection after open surgical treatment. ${ }^{48}$ Some studies have also associated female sex with a higher prevalence of lower extremity bleeding complications after surgical bypass. ${ }^{49}$ These findings suggest that an endovascular-first option for revascularization in females may be beneficial.

In the past decade, the introduction and widespread adaptation of endovascular techniques has led to a paradigm shift in the treatment of PAD. Fortunately, this has led to the treatment of patients with CLI who may have been excluded from surgical revascularization in the past. However, as endovascular treatment is still in its relative infancy, there are sparse data in the literature analyzing the impact of sex on the endovascular treatment of PAD. Similar to studies in the surgical literature, women presenting with an indication for endovascular intervention are generally older at presentation, and are more likely to present with CLI than men.

There are some data to suggest that women have different outcomes than men after percutaneous intervention. In a single-center review of infrainguinal percutaneous intervention, rates of amputation and conversion to surgical bypass were similar. ${ }^{50}$ Findings of other studies examining genderbased differences in outcomes relating to percutaneous procedures have had demonstrated other gender-based differences. In a registry of 12,379 patients undergoing 
percutaneous intervention, female sex was associated with a higher rate of technical success than men. However, in this same registry, the rates of vascular complications, transfusions, and embolic events were higher when compared with men (men and women 79.7 vs. $81.6 \%, p=0.08) .{ }^{51}$ It seems that women may be more prone to complications as a result of either open or endovascular revascularization. Endovascular intervention generally in females appears to be associated with better patency rates and may be associated with better outcomes in cases of CLI when compared with males presenting with CLI. ${ }^{52}$ The optimal intervention based on gender and indication is not clearly delineated in the literature, and remains a topic for future study.

\section{Endovascular Treatment of PAD: Gender and Technique Considerations}

Percutaneous vascular intervention (PVI) has been traditionally recommended for patients with type A or B Transatlantic InterSociety Consensus (TASCII) disease, those with favorable anatomy, patients who are poor surgical candidates, or in patients where surgery would result in significant morbidity. ${ }^{53}$ The aforementioned studies raise some important questions when it comes to treatment modalities based on anatomic location, gender, and indication. There is some evidence that percutaneous intervention may have some gender-related advantages depending on lesion location.

Surgical revascularization remains the preferred strategy for the treatment of disease in the common femoral or popliteal arteries. External factors play a role in the high failure rates of intervention in these areas, as these arteries are subject to external compression due to flexion and extension forces of the hip and knee. In patients who are not candidates for surgical revascularization, endovascular interventions such as balloon angioplasty, drug-coated balloon angioplasty, and atherectomy remain options for treatment of these areas without the use of implantable stents. In general, stenting of these areas should be of absolute last resort. The greater compression, stretch, and torsion in areas of these arteries that overlie the knee and hip predispose to stent fracture, kinking, or dissociation in the case of overlapping stents. In the common femoral artery, stenting can compromise future endarterectomy, future bypass, and also put the profunda femoris artery ostium at risk for complication. Therefore, the placement of an implantable device in these areas should be avoided unless surgery will not be an option for the patient going forward.

Treatment of iliac occlusive disease in both males and females is better suited for an endovascular approach. The complex nature of the lesions, ease of femoral access, and durability of both angioplasty and stenting provide optimal conditions for endovascular treatment. A more aggressive "stent-first" strategy has been employed at many institutions for the treatment of iliac disease. The heavily calcified nature of the plaques in the iliac vessels predisposes treatment with angioplasty alone to vessel recoil and dissection. In a recent meta-analysis with 958 patients treated with primary stenting, stenting and percutaneous transluminal angioplasty (PTA) resulted in similar 1- and 2-year patency rates, but primary stenting was associated with far fewer complications than PTA alone ( 5 vs. $20 \%$ complication rate). ${ }^{54}$ While both balloon angioplasty and stenting are viable treatment strategies in the iliac vessels, primary stenting may be the preferred strategy given the lower rates of complication. There is some suggestion that gender-based differences are present in the treatment of iliac stenosis. In 2001, Timaran et al reported that females had decreased patency rates associated with stented iliac lesions. ${ }^{55}$ More recently, however, these data have been refuted. In 2014, cases of iliac-occlusive disease were examined for gender differences in outcomes and showed no difference in primary or secondary patency rates of iliac stenting based on gender, despite women having an older age at presentation and more extensive occlusive disease. ${ }^{56}$ This suggests that women treated with iliac stenting may have similar outcomes than men when presenting with a greater burden of occlusive disease.

The superficial femoral artery (SFA) is the most common location of an occlusive atherosclerotic focus in the lower extremity. The SFA is the longest artery in the body, and it takes a tortuous course within the muscular adductor canal. When contemplating endovascular treatment of the SFA, one must consider the unique anatomic considerations of this artery, as well as the unique mechanical stressors on this artery due to thigh contraction. The adductor canal serves at the point of maximum force on this artery during walking, and often is a precipitating site of atherosclerotic disease. Although stent patency is inversely related to compression and mobility, stenting should be reserved for low anatomic stress areas or in cases of long segment disease. The Femoral Artery Stenting Trial (FAST) suggested that for lesions of the SFA less than $10 \mathrm{~cm}$, angioplasty alone had no difference compared with self-expandable stenting. ${ }^{57}$ Given these data, one can consider angioplasty with provisional stenting for short segment lesions. For lesions greater than $10 \mathrm{~cm}$ in length, stenting has shown superior patency rates as compared with conventional angioplasty. ${ }^{58}$ Certain studies suggest that patency rates after infrainguinal intervention are better in women than in men when the indication is CLI. Gallagher et al showed that women have better patency rates in PTA and stenting of the SFA than men when treated with balloon angioplasty or stenting alone. ${ }^{52}$ These limited data, combined with surgical data indicative of an increased complication rates in women undergoing bypass, suggest that endovascular intervention in females may be the preferred treatment modality for SFA lesions.

Infrapopliteal intervention is typically reserved for patients with CLI. At this stage of disease, severely calcified vessels, high-grade stenosis, and long segment or multivessel total occlusions often complicate the treatment of the tibial vessels. Additionally, microvascular disease can limit outflow and cause early rethrombosis of target vessels. In patients who present with a single viable distal runoff vessel, the odds of precipitating an episode of acute limb ischemia should be weighed against the benefit of intervention should an embolic or thrombotic event occur. Numerous studies support the use 
Table 3 Therapy outcomes of PAD in women

\begin{tabular}{|c|c|}
\hline Medical therapy, cilostazol & No gender-based difference to benefit ${ }^{38}$ \\
\hline Supervised exercise & No gender-based difference to benefit ${ }^{41}$ \\
\hline \multicolumn{2}{|l|}{ Surgical revascularization outcomes } \\
\hline Graft failure & Higher incidence in women ${ }^{47-49}$ \\
\hline Wound infection & Higher incidence in women ${ }^{47-49}$ \\
\hline Bleeding complications & Higher incidence in women ${ }^{47-49}$ \\
\hline Limb loss after surgery & Higher incidence in women ${ }^{47-49}$ \\
\hline Mortality & Higher incidence in women ${ }^{47-49}$ \\
\hline \multicolumn{2}{|l|}{ Endovascular revascularization outcomes } \\
\hline Technical success & Higher incidence in women ${ }^{51}$ \\
\hline Embolic events & Higher incidence in women ${ }^{51}$ \\
\hline Patency rates after $\mathrm{CLI}$ & Higher in women ${ }^{52}$ \\
\hline Limb loss after EVI & Similar for males and females ${ }^{52}$ \\
\hline Outcomes after iliac stenting & Similar primary and secondary patency ${ }^{56}$ \\
\hline Outcomes after SFA POBA/stenting & Improved patency in females ${ }^{52}$ \\
\hline Outcomes after tibial angioplasty & Improved patency in females ${ }^{52}$ \\
\hline
\end{tabular}

Abbreviations: CLI, critical limb ischemia; EVI, endovascular intervention; PAD, peripheral arterial disease; POBA, plain old balloon angioplasty; SFA, superficial femoral artery.

of balloon angioplasty for treatment of infrapopliteal disease, and this remains the treatment of choice for below the knee disease. $^{59}$ Even in complicated disease, more than $90 \%$ limb salvage rates have been reported with angioplasty alone. ${ }^{60}$ Unfortunately, much of these data have not been evaluated for outcomes based on gender. Gallagher et al reported a statistically significant patency rate at all time points $(0,6,12,18$, and 24 months) in females as compared with males following tibial angioplasty. Additionally, limb salvage was significantly greater for females at all time points in the PTA group. ${ }^{52}$ Stenting can be considered for refractory or calcified lesions. Data regarding gender-specific differences in infrapopliteal stenting are sparse. The ACHILLES trial randomized 200 patients to drug-eluting stent (DES) or angioplasty for infrapopliteal disease and showed decreased rates of angiographic restenosis and improved vessel patency with DES. These data were sorted for sex-dependent outcomes; however, no gender-specific differences were noted. ${ }^{61}$ Both PTA and stenting remain viable strategies for treatment of infrapopliteal lesions in women, and women may have better outcomes with respect to men.

- Table 3 outlines treatment outcomes of medical and interventional treatments of PAD in women.

\section{Conclusion}

PAD remains an under-recognized disease entity for women. Women who present with symptomatic PAD tend to be older than their male counterparts and are more likely to present with CLI than men. Despite these differences, endovascular treatment of PAD in women remains a viable and durable option. There is a continued need for targeted health cam- paigns for women to promote early management of risk factors, early diagnosis, and management of PAD.

\section{References}

1 Kochanek KD, Murphy SL, Xu J, Tejada-Vera B. Deaths: final data for 2014. Natl Vital Stat Rep 2016;65(04):1-122

2 Taylor SM. Commentary. Gaps in public knowledge of peripheral arterial disease: the first national PAD public awareness survey. Perspect Vasc Surg Endovasc Ther 2008;20(03):314-316

3 Wenger NK. Women and coronary heart disease: a century after Herrick: understudied, underdiagnosed, and undertreated. Circulation 2012;126(05):604-611

4 Mahoney EM, Wang K, Cohen DJ, et al; REACH Registry Investigators. One-year costs in patients with a history of or at risk for atherothrombosis in the United States. Circ Cardiovasc Qual Outcomes 2008;1(01):38-45

5 Walker JP, Hiramoto JS. Diagnosis and management of peripheral artery disease in women. Int J Womens Health 2012;4:625-634

6 Hoel AW, Kayssi A, Brahmanandam S, Belkin M, Conte MS, Nguyen LL. Under-representation of women and ethnic minorities in vascular surgery randomized controlled trials. J Vasc Surg 2009;50(02):349-354

7 Mendis S, Puska P, Norrving B. Global Atlas on Cardiovascular Disease Prevention and Control. World Health Organization; 2011

8 Kuller LH, Matthews KA, Edmundowicz D, Chang Y. Incident coronary artery calcium among postmenopausal women. Atherosclerosis 2008;200(02):278-285

9 Daviglus ML, Stamler J, Pirzada A, et al. Favorable cardiovascular risk profile in young women and long-term risk of cardiovascular and all-cause mortality. JAMA 2004;292(13):1588-1592

10 Willigendael EM, Teijink JA, Bartelink M-L, et al. Influence of smoking on incidence and prevalence of peripheral arterial disease. J Vasc Surg 2004;40(06):1158-1165

11 Price JF, Mowbray PI, Lee AJ, Rumley A, Lowe GD, Fowkes FG. Relationship between smoking and cardiovascular risk factors in the development of peripheral arterial disease and coronary 
artery disease: Edinburgh Artery Study. Eur Heart J 1999;20(05): 344-353

12 Jamal A, Homa DM, O'Connor E, et al. Current cigarette smoking among adults - United States, 2005-2014. MMWR Morb Mortal Wkly Rep 2015;64(44):1233-1240

13 Westendorp IC, in't Veld BA, Grobbee DE, et al. Hormone replacement therapy and peripheral arterial disease: the Rotterdam study. Arch Intern Med 2000;160(16):2498-2502

14 Rossouw JE, Anderson GL, Prentice RL, et al; Writing Group for the Women's Health Initiative Investigators. Risks and benefits of estrogen plus progestin in healthy postmenopausal women: principal results from the Women's Health Initiative randomized controlled trial. JAMA 2002;288(03):321-333

15 Grady D, Herrington D, Bittner V, et al; HERS Research Group. Cardiovascular disease outcomes during 6.8 years of hormone therapy: Heart and Estrogen/progestin Replacement Study follow-up (HERS II). JAMA 2002;288(01):49-57

16 Hsia J, Criqui MH, Herrington DM, et al; Women's Health Initiative Research Group. Conjugated equine estrogens and peripheral arterial disease risk: the Women's Health Initiative. Am Heart J 2006;152(01):170-176

17 Pyörälä K, Laakso M, Uusitupa M. Diabetes and atherosclerosis: an epidemiologic view. Diabetes Metab Rev 1987;3(02): 463-524

18 Brun E, Nelson RG, Bennett PH, et al; Verona Diabetes Study. Diabetes duration and cause-specific mortality in the Verona Diabetes Study. Diabetes Care 2000;23(08):1119-1123

19 Kannel WB, McGee DL. Update on some epidemiologic features of intermittent claudication: the Framingham Study. J Am Geriatr Soc 1985;33(01):13-18

20 Smith SC Jr, Haslam D. Abdominal obesity, waist circumference and cardio-metabolic risk: awareness among primary care physicians, the general population and patients at risk-the Shape of the Nations survey. Curr Med Res Opin 2007;23(01):29-47

21 Cabrera MA, Gebara OC, Diament J, Nussbacher A, Rosano G, Wajngarten M. Metabolic syndrome, abdominal obesity, and cardiovascular risk in elderly women. Int J Cardiol 2007;114(02):224-229

22 Berg AH, Scherer PE. Adipose tissue, inflammation, and cardiovascular disease. Circ Res 2005;96(09):939-949

23 Giusti V. Management of obesity in patients with peripheral arterial disease. Eur J Vasc Endovasc Surg 2007;34(05):576-582

24 Yao ST, Hobbs JT, Irvine WT. Ankle systolic pressure measurements in arterial disease affecting the lower extremities. Br J Surg 1969;56(09):676-679

25 Rooke TW, Hirsch AT, Misra S, et al; American College of Cardiology Foundation/American Heart Association Task Force on Practice Guidelines; Society for Cardiovascular Angiography and Interventions; Society of Interventional Radiology; Society for Vascular Medicine; Society for Vascular Surgery. 2011 ACCF/ AHA Focused update of the guideline for the management of patients with peripheral artery disease (updating the 2005 guideline): A Report of the American College of Cardiology Foundation/American Heart Association Task Force on Practice Guideline. J Vasc Surg 2011;54(05):e32-e58

26 Criqui MH, Aboyans V. Epidemiology of peripheral artery disease. Circ Res 2015;116(09):1509-1526

27 Allison MA, Ho E, Denenberg JO, et al. Ethnic-specific prevalence of peripheral arterial disease in the United States. Am J Prev Med 2007;32(04):328-333

28 Hirsch AT, Allison MA, Gomes AS, et al. A call to action: women and peripheral artery disease. Circulation 2012;125(11):1449-1472

29 Diehm C, Schuster A, Allenberg JR, et al. High prevalence of peripheral arterial disease and co-morbidity in 6880 primary care patients: cross-sectional study. Atherosclerosis 2004;172 (01):95-105

30 Hirsch AT, Criqui MH, Treat-Jacobson D, et al. Peripheral arterial disease detection, awareness, and treatment in primary care. JAMA 2001;286(11):1317-1324
31 Sigvant B, Wiberg-Hedman K, Bergqvist D, et al. A populationbased study of peripheral arterial disease prevalence with special focus on critical limb ischemia and sex differences. J Vasc Surg 2007;45(06):1185-1191

32 McDermott MM, Greenland P, Liu K, et al. The ankle brachial index is associated with leg function and physical activity: the Walking and Leg Circulation Study. Ann Intern Med 2002;136(12):873-883

33 McDermott MM, Fried L, Simonsick E, Ling S, Guralnik JM. Asymptomatic peripheral arterial disease is independently associated with impaired lower extremity functioning: the women's health and aging study. Circulation 2000;101(09):1007-1012

34 McDermott MM, Greenland P, Liu K, et al. Sex differences in peripheral arterial disease: leg symptoms and physical functioning. J Am Geriatr Soc 2003;51(02):222-228

35 Mazhari R, Hsia J. Prevalence, clinical significance, and management of peripheral arterial disease in women: is there a role for postmenopausal hormone therapy? Vasc Health Risk Manag 2005;1(02):111-117

36 Hobbs SD, Bradbury AW. Smoking cessation strategies in patients with peripheral arterial disease: an evidence-based approach. Eur J Vasc Endovasc Surg 2003;26(04):341-347

37 Robless P, Mikhailidis DP, Stansby GP. Cilostazol for peripheral arterial disease. Cochrane Database Syst Rev 2008;(01):CD003748

38 Pande RL, Hiatt WR, Zhang P, Hittel N, Creager MA. A pooled analysis of the durability and predictors of treatment response of cilostazol in patients with intermittent claudication. Vasc Med 2010;15(03):181-188

39 Lane R, Ellis B, Watson L, Leng GC. Exercise for intermittent claudication. Cochrane Database Syst Rev 2014;(07):CD000990

40 Conte MS, Pomposelli FB, Clair DG, et al; Society for Vascular Surgery Lower Extremity Guidelines Writing Group; Society for Vascular Surgery. Society for Vascular Surgery practice guidelines for atherosclerotic occlusive disease of the lower extremities: management of asymptomatic disease and claudication. J Vasc Surg 2015;61(3, Suppl):2S-41S

41 Lundgren F, Dahllöf AG, Lundholm K, Scherstén T, Volkmann R. Intermittent claudication-surgical reconstruction or physical training? A prospective randomized trial of treatment efficiency. Ann Surg 1989;209(03):346-355

42 Trialists'Collaboration A; Antithrombotic Trialists' Collaboration. Collaborative meta-analysis of randomised trials of antiplatelet therapy for prevention of death, myocardial infarction, and stroke in high risk patients. BMJ 2002;324(7329):71-86

43 Belch J, MacCuish A, Campbell I, et al; Prevention of Progression of Arterial Disease and Diabetes Study Group; Diabetes Registry Group; Royal College of Physicians Edinburgh. The prevention of progression of arterial disease and diabetes (POPADAD) trial: factorial randomised placebo controlled trial of aspirin and antioxidants in patients with diabetes and asymptomatic peripheral arterial disease. BMJ 2008;337:a1840

44 Feinglass J, McDermott MM, Foroohar M, Pearce WH. Gender differences in interventional management of peripheral vascular disease: evidence from a blood flow laboratory population. Ann Vasc Surg 1994;8(04):343-349

45 Egorova N, Vouyouka AG, Quin J, et al. Analysis of gender-related differences in lower extremity peripheral arterial disease. J Vasc Surg 2010;51(02):372-8.e1, discussion 378-379

46 Lancaster RT, Conrad MF, Patel VI, Cambria RP, LaMuraglia GM. Predictors of early graft failure after infrainguinal bypass surgery: a risk-adjusted analysis from the NSQIP. Eur J Vasc Endovasc Surg 2012;43(05):549-555

47 Nguyen LL, Brahmanandam S, Bandyk DF, et al. Female gender and oral anticoagulants are associated with wound complications in lower extremity vein bypass: an analysis of 1404 operations for critical limb ischemia. J Vasc Surg 2007;46(06):1191-1197

48 Jain AK, Velazquez-Ramirez G, Goodney PP, Edwards MS, Corriere MA. Gender-based analysis of perioperative outcomes associated with lower extremity bypass. Am Surg 2011;77(07):844-849 
49 Vouyouka AG, Egorova NN, Salloum A, et al. Lessons learned from the analysis of gender effect on risk factors and procedural outcomes of lower extremity arterial disease. J Vasc Surg 2010; 52(05):1196-1202

50 Pulli R, Dorigo W, Pratesi G, Fargion A, Angiletta D, Pratesi C. Gender-related outcomes in the endovascular treatment of infrainguinal arterial obstructive disease. J Vasc Surg 2012;55(01): 105-112

51 Jackson EA, Munir K, Schreiber T, et al. Impact of sex on morbidity and mortality rates after lower extremity interventions for peripheral arterial disease: observations from the Blue Cross Blue Shield of Michigan Cardiovascular Consortium. J Am Coll Cardiol 2014;63(23):2525-2530

52 Gallagher KA, Meltzer AJ, Ravin RA, et al. Gender differences in outcomes of endovascular treatment of infrainguinal peripheral artery disease. Vasc Endovascular Surg 2011;45(08): 703-711

53 Norgren L, Hiatt WR, Dormandy JA, et al; TASC II Working Group. Inter-society consensus for the management of peripheral arterial disease (TASC II). Eur J Vasc Endovasc Surg 2007;33(01, Suppl 1): S1-S75

54 Goode SD, Cleveland TJ, Gaines PA; STAG Trial Collaborators. Randomized clinical trial of stents versus angioplasty for the treatment of iliac artery occlusions (STAG trial). Br J Surg 2013; 100(09):1148-1153
55 Timaran CH, Stevens SL, Freeman MB, Goldman MH. External iliac and common iliac artery angioplasty and stenting in men and women. J Vasc Surg 2001;34(03):440-446

56 Bechter-Hugl B, Falkensammer J, Gorny O, Greiner A, Chemelli A Fraedrich $G$. The influence of gender on patency rates after iliac artery stenting. J Vasc Surg 2014;59(06):1588-1596

57 Krankenberg H, Schlüter M, Steinkamp HJ, et al. Nitinol stent implantation versus percutaneous transluminal angioplasty in superficial femoral artery lesions up to $10 \mathrm{~cm}$ in length: the femoral artery stenting trial (FAST). Circulation 2007;116(03):285-292

58 Tadros RO, Vouyouka AG, Ting W, et al. A review of superficial femoral artery angioplasty and stenting. J Vasc Med Surg 2015; $3: 183$

59 Romiti M, Albers M, Brochado-Neto FC, Durazzo AES, Pereira CAB, De Luccia N. Meta-analysis of infrapopliteal angioplasty for chronic critical limb ischemia. J Vasc Surg 2008;47(05):975-981

60 Schmidt A, Ulrich M, Winkler B, et al. Angiographic patency and clinical outcome after balloon-angioplasty for extensive infrapopliteal arterial disease. Catheter Cardiovasc Interv 2010;76(07):1047-1054

61 Scheinert D, Katsanos K, Zeller T, et al; ACHILLES Investigators. A prospective randomized multicenter comparison of balloon angioplasty and infrapopliteal stenting with the sirolimus-eluting stent in patients with ischemic peripheral arterial disease: 1year results from the ACHILLES trial. J Am Coll Cardiol 2012;60 (22):2290-2295 